uniform and quite independent of the diameters of the pseudopodia. Hence their movement cannot be compared to the flow of a viscous liquid in a tube.

(3) The flow is not influenced in any way by contact with a solid substratum, a fact which is quite inconsistent with any simple interpretation based on surface tension differences. Normal streaming of granules takes place even in pseudopodia having no free tip (that is, running from one part of the periphery of an animal to another part), and so can have nothing to do with conditions at the tip or with any kind of physiological gradient between the tip and the base. There is likewise no evidence of any reversible sol-gel process or of any contracting tube of plasma-gel.

(4) Injurious stimuli (chemical or thermal) cause the pseudopodia to break into liquid droplets, or, less commonly, into short rods. These two reactions might appear to represent the effects of increased and decreased fluidity respectively, but this explanation does not fit in with the known effects of the stimuli in question on other kinds of protoplasm. In fact, sometimes a single stimulus produces both of the reactions simultaneously in different parts of a single individual. If the stability of the threads depends upon the presence of a relatively solid axial structure, it seems strange that reagents which normally increase the viscosity of protoplasm should cause the threads to break into drops. Cyanide causes a cessation of movement without any immediate disintegration, so stability of the threads does not depend upon movement as suggested by Lepeschkin ${ }^{2}$.

Faculty of Science,

Egyptian University, Cairo.

1 Quoted by Jensen, Arch. ges. Physiol., 87 ; 1901.

2 Biologia generalis, 1,1925 .

\section{A Rapid Test for Pregnancy on Xenopus lævis}

Is a recent communication Bellerby $(1933)^{1}$ has shown that injection of acid or alkaline extracts of bovine anterior lobe of the pituitary gland into female South African clawed toads (Xenopus loevis) produces extrusion of ova through the cloaca within 18 hours.

The well-known Zondek-Ascheim test, or its modification by Friedman, using the rabbit, is based on the occurrence in the urine of pregnancy of an anterior pituitary-like gonado-kinetic hormone.

These considerations led us to investigate the possibilities of Xenopus laevis as a test animal for pregnancy. The urine is detoxicated, precipitated and concentrated according to the method of Zondek $(1930)^{2}$. The aqueous extract is injected into each of six female South African clawed toads. Twelve to eighteen hours later at room temperature, that is, about $18^{\circ} \mathrm{C}$., a positive reaction is indicated by either (a) extrusion of macroscopic ova through the cloaca, or $(b)$ post-mortem examination of the animal (in the absence of ovulation), when one ovum or more is seen in either or both of the oviducts. If $(a)$ occurs in any one animal, post-mortem examination of the remaining animals is unnecessary. A negative test is repeated on a further six animals.

At higher temperatures, for example, about $27^{\circ} \mathrm{C}$, the reaction is speeded up considerably and ovulation has already occurred so soon as 5-6 hours after injection.
In a series of 97 cases investigated by this method to date, 52 correct positive and 45 correct negative findings have been recorded.

Xenopus is a suitable test animal as it does not ovulate spontaneously under laboratory conditions. As a matter of fact, in about 250 toads fresh from the ponds examined during the breeding season, no ova were detected in the oviducts (Zwarenstein and Shapiro, 1933) ${ }^{3}$. However, during the breeding season (July to September in South Africa) as an additional precaution it is necessary that the test animals from the ponds should be isolated under laboratory conditions for at least one week and controls killed and examined.

We have observed that if the toads have been maintained under laboratory conditions for longer than three to four weeks, they appear to undergo a desensitisation to the urinary prolan, when incorrect negatives may be obtained. The laboratory age of the test animals should therefore not exceed three to four weeks.

The advantages of the test are as follows :-

1. The test animal is cheap, easily available and inexpensive to maintain.

2. It is not necessary in the majority of cases to kill the test animal, as it is with rats, mice and rabbits.

3. The extremely short time taken for the test16-18 hours at room temperature $\left(18^{\circ}-20^{\circ}\right.$ C.). A technique for further shortening the post-injection latent interval is being investigated.

4. The simplicity of the end-reaction-extrusion of easily visible ova through the cloaca or their presence in the ducts. In Amphibia, extrusion of the ova is a sufficiently obvious and unequivocal phenomenon.

5. Small volumes of aqueous extract may be injected into the test animal, in a single dose, repeated and divided doses being unnecessary.

Although extrusion of ova does not occur in Rana after injection of anterior pituitary extract ${ }^{4}$, a reaction is obtained in the oviducts and this indicates the possibility of using Rana also as a test animal.

In collaboration with Dr. A. I. Goldberg the test is being applied in the investigation of cases of endocrine anomalies.

\author{
Department of Physiology, \\ University of Cape Town. \\ April 12. \\ ${ }^{1}$ Bellerby, C. W., Biochem. J., 27, 615; 1933. \\ Zondek, B., Klin. Wochenschr ., 9, 964; 1930. \\ Zwarenstein, H., and Shapiro, H. A., J. Exp. Biol., 10, 372 ; 1933.
}

H. A. Shapiro.

H. ZWARENSTEIN.

\section{A New Guinea Fish Poison}

UNDER this heading Prof. A. K. Macbeth refers in Nature of April 28, p. 649, to a probable Derris species, the native name of which he gives as Tua or Tuva. Without any philological gymnastics, this name is evidently a variant on the Malay name $T u b a$, applied to various Derris species. In Polynesia I believe that the word is also softened to Duva or Tuva.

Further information on the use of $T u b a$ will be found in the late J. D. Gimlette's "Malay Poisons and Charm Cures" (third ed., 1929, p. 240 et seq.).

Dunelm, H. E. Durham. Hereford. 